\title{
ENSAIOS DE INOVAÇÃO NO ENSINO MÉDIO
}

\author{
ELENY MITRULIS \\ Faculdade de Educação da Universidade de São Paulo \\ mitrulis@uol.com.br
}

\section{RESUMO}

O objetivo deste trabalho é examinar alguns ensaios de inovação que vêm ocorrendo no ensino de nível médio e destacar elementos que possam contribuir para sua interpretação bem como para a formulação de políticas de apoio e de orientação às escolas. Em um primeiro momento, examinam-se a centralidade do ensino médio no conjunto das reformas educativas, o direcionamento destas reformas no contexto da mudança do papel do Estado e as questões relativas à formação geral e à formação profissional. A segunda parte deste ensaio é dedicada ao exame de alguns conceitos de reforma e de inovação e à descrição e análise de relatos de experiências e ensaios de inovação realizados por escolas de nível médio. São relatos apresentados por escolas públicas estaduais que participaram da primeira fase do Programa de Expansão e Melhoria do Ensino Médio da Secretaria de Estado da Educação de São Paulo', entre os anos 2000 e 2001. Os relatos apresentados, com exceção daqueles referentes à gestão da aplicação dos recursos financeiros distribuídos pelo programa, referem-se a ensaios de inovação realizados pelas escolas antes de sua vinculação a ele. ENSINO MÉDIO - ENSINO DE $2^{\circ}$ GRAU - ESCOLAS PÚBLICAS - REFORMA DO ENSINO - INOVAÇÃO

I. O Programa de Expansão e Melhoria do Ensino Médio da Secretaria de Estado da Educação de São Paulo visa oferecer às escolas apoio financeiro e técnico para o desenvolvimento de seus projetos pedagógicos à luz das diretrizes para o ensino médio contidas na nova Lei de Diretrizes e Bases da Educação Nacional - LDB -, Lei 9.394/96, e das Diretrizes Curriculares Nacionais do Ensino Médio, Resolução n. 15 de 1998 do Conselho Nacional de Educação. Participaram, em sua primeira etapa, 192 escolas, que correspondem aproximadamente a 10\% do total da rede pública estadual, escolhidas dentre um grupo de instituições que se inscreveu voluntariamente para participar. Os critérios de seleção utilizados garantiram um perfil heterogêneo do conjunto das escolas, que foram avaliadas segundo índices de evasão e repetência, equipamentos de informática e laboratórios, estabilidade do corpo docente, projetos desenvolvidos e em desenvolvimento, desempenho em avaliação externa, entre outros. Portanto, as escolas selecionadas constituíram um conjunto que variou desde as menos aquinhoadas em termos de recursos disponíveis e de baixo desempenho até as melhores, situadas no topo do ranking de avaliação, numa distribuição próxima a uma curva normal. 


\begin{abstract}
This article aims to examine some of the experiences implemented at the mid level and to highlight elements that can contribute to their interpretation as well as the formulation of policies to support and guide the schools. First, the centrality of mid level education to the body of educational reforms is examined, the nature of these reforms in the context of the changing role of the State and issues referring to training in general and of professionals. The second part is dedicated to an examination of some concepts of reform and of innovation and a description and analysis of reports of experiences and trails of innovations realized by mid level schools. These are reports presented by state public schools which participated in the first phase of the Program to Improve and Expand Mid level Teaching of the São Paulo State Department of Education in 2000 and 2001. The reports presented, with the exception of those that refer to managing the application of financial resources distributed by the program, refer to trials of innovations realized by schools prior to their connection to the program. SECONDARY EDUCATION - PUBLIC SCHOOLS - EDUCATIONAL REFORM INNOVATION
\end{abstract}

\title{
A CENTRALIDADE DO ENSINO MÉDIO NO CENÁRIO EDUCACIONAL BRASILEIRO
}

O ensino médio ocupa lugar de destaque, dentre os diferentes níveis de ensino, quando se considera o conjunto de transformações pelas quais vem passando recentemente o sistema educacional do país. No que se refere à educação básica, pode-se dizer que, no Brasil, a primeira metade do século $X X$ assistiu a uma concentração de esforços para institucionalizar e difundir a etapa inicial de quatro anos do ensino fundamental e que, na segunda metade deste mesmo século, tal empenho esteve dirigido à ampliação da oferta de educação obrigatória para oito anos de escolaridade, procurando abranger o universo da população até os 14 anos. Os indicadores educacionais revelam que os desafios relativos à cobertura das diferentes coortes de idade correspondentes ao ensino fundamental completo foram enfrentados com algum sucesso, uma vez que $96 \%$ da população da faixa etária correspondente está neste nível de ensino. Persistem, entretanto, problemas como: defasagem idade-série, uma vez que $46 \%$ dos alunos do ensino fundamental têm idade superior à faixa etária correspondente a cada série; longo tempo de percurso, 10,4 anos, para completar um processo de escolarização previsto para 8 anos; e baixo nível de desempenho, que se reflete em índices ainda expressivos de abandono e reprovação, 13,7\% e 7,5\% respectivamente, num total de 21 ,2\% de perda. São desafios que vêm sendo enfrentados com medidas promissoras tal como 
revelam os indicadores decrescentes de atraso, tempo de percurso e perda. ${ }^{2}$ Neste contexto, é para o ensino médio que se volta no momento a política educacional do país, comprometida, à semelhança dos países mais desenvolvidos, com projetos direcionados à modernização e à democratização social.

Nos países desenvolvidos, que apresentam um nível expressivo de inclusão dos diferentes segmentos sociais no processo de escolarização básica, a atenção maior é dirigida às demandas do processo de modernização. Busca-se oferecer um novo tipo de formação no nível médio, diante das transformações nos modos de produção e de gestão do trabalho, decorrentes do desenvolvimento científico e tecnológico, com efetiva repercussão nas relações sociais e na esfera política e cultural da sociedade. Nem o ensino médio propedêutico aos estudos superiores, em regra de currículo enciclopédico, recheado de conhecimentos pouco significativos, caracterizados por uma rala aderência à experiência dos alunos e aos desafios sociais, nem o ensino médio profissionalizante, estritamente voltado para o exercício de ocupações específicas no mercado de trabalho, respondem às expectativas atuais. $\bigcirc$ ensino médio é chamado a contribuir para uma formação mais geral e equilibrada dos indivíduos, atentando para o desenvolvimento de competências sociais, cognitivas e afetivas, pautadas por valores de inclusão e protagonismo social, que os qualifiquem a participar de um projeto de modernização e democratização da sociedade.

Nos países emergentes, a estes desafios outros se agregam, tornando sobremaneira complexa a tarefa. Entre eles, o desafio da dívida social de universalização de contingentes até aqui não incluídos no processo de escolarização. Neste particular, o Brasil encontra-se em situação de especial desvantagem quando comparado a seus irmãos latino-americanos do continente. Enquanto já na primeira metade do século XX a Argentina, o Chile e o Uruguai exibiam altas taxas de escolarização das suas populações, o Brasil somente se interessou em incorporar as camadas populares no rol dos cidadãos escolarizados a partir de meados do século, com o início do processo de industrialização. Nos anos 60 ainda contávamos com 40\% da população analfabeta. A "escola de qualidade" tem sido uma escola de classe média, branca e urbana, marcada por alta seletividade interna.

Essa é uma das razões pelas quais, apesar da oferta de vagas na I a série do ensino médio ser consideravelmente superior ao número de egressos do ensino

2. Fonte dos dados referidos no parágrafo: BRASIL/MEC/Inep/Seec. Informes Estatísticos, 1996 e Censo escolar, 1998 
fundamental, o acesso a este nível de ensino ainda ser reduzido. A taxa de matrícula é de apenas 30,8\% da população de 15 a 17 anos, o que o caracteriza, segundo Mello (1999, p. 9|), como um ensino de minorias sobreviventes do ensino fundamental. Cabe registrar, ainda, que se trata de um ensino, em sua grande maioria, de responsabilidade da esfera pública e concentrado no período noturno, quer por questão de oferta, ocupação de espaços ociosos do ensino fundamental, quer por questão de demanda, uma vez que se trata de jovens já em idade apropriada para a inserção no mundo do trabalho, os quais, se não estão empregados, estão permanentemente em busca de trabalho remunerado. Os estados da federação comparecem com $76,0 \%$ das matrículas, mais de $54,8 \%$ das quais estão vinculadas a cursos que funcionam à noite, cujas taxas de desempenho são marcadamente inferiores às dos cursos diurnos.

Embora estes indicadores revelem uma situação muito aquém das necessidades sociais, econômicas e políticas do país, os índices de melhoria do ensino médio registrados na última década são expressivos. Este é o nível de ensino que apresentou a maior taxa de crescimento nos últimos anos em todo o sistema. Algumas das razões são a ampliação da oferta e a melhoria da qualidade do ensino fundamental, que resultaram na queda dos índices de abandono e repetência e na elevação das taxas de conclusão do curso. Outro fator é o retorno aos bancos escolares de um contingente da população que havia interrompido a continuidade dos estudos, movido pelas novas exigências do sistema produtivo. Uma ilustração do que se afirma é a avaliação externa dos convênios firmados no âmbito do Plano Nacional de Qualificação do Trabalhador - Planfor -, com recursos do Fundo de Amparo ao Trabalhador - FAT -, com vistas à realização de cursos de requalificação de desempregados. Esta avaliação, realizada em 1998 pela Unitrabalho, fundação de entidades de ensino superior para estudos relativos ao mercado de trabalho, revela que os egressos destes cursos mais beneficiados com recolocação são os portadores de diploma de ensino médio. Poucas chances há para aqueles que apenas cursaram o ensino fundamental. $\bigcirc$ ensino médio já constitui o patamar mínimo de escolaridade exigido para as atividades de "chão de fábrica".

A incorporação de grupos sociais antes excluídos da continuidade de estudos, egressos do ensino fundamental, e o retorno dos que haviam deixado a escola criam um quadro no qual se alia, de um lado, uma grande explosão da demanda, e de outro, uma acentuada diferenciação da clientela. Este é o outro desafio relevante do projeto de modernização e democratização social do país, que tem na reformulação do ensino médio uma de suas dimensões mais importantes. 
Enquanto nas etapas iniciais do processo de escolarização, a estrutura e o funcionamento dos sistemas educacionais, em geral, estiveram fundamentados no paradigma positivista da homogeneidade e controle, nas etapas mais avançadas do processo educativo a concepção social foi seletiva e meritocrática. Consolidou-se, em conseqüência, uma cultura de expectativas, em relação aos alunos do ensino médio e ao processo de formação aí desenvolvido, bastante distante dos princípios e diretrizes mais democráticos que passaram a nortear as propostas de renovação do ensino médio na última década. Ou seja, consolidou-se uma cultura segregacionista voltada para uma destinação social especíica e distinta dos diferentes segmentos sociais, que se contrapõe à proposta atual de ensino médio de formação geral como direito subjetivo de todo e qualquer cidadão do país, independentemente da regularidade do seu percurso escolar, do apoio cultural do meio familiar e dos projetos de vida pessoal.

O ensino médio que tende à universalização vem registrando uma mudança significativa na composição social, econômica e cultural de seus alunos. A ele passam a ter acesso jovens procedentes dos estratos populares menos favorecidos economicamente, com pouco apoio cultural do meio familiar de origem, que realizaram um percurso escolar acidentado, mais longo, entremeado por reprovações, afastamentos, motivados ou não por necessidades de trabalho. São jovens que estão em busca de, ou já alcançaram, autonomia na vida pessoal e profissional, portadores de visões de mundo, trajetórias de vida, experiências profissionais, convicções políticas e religiosas e compromissos familiares diversos. $\bigcirc$ tempo que esses alunos permanecem na escola requer uma administração diferente.

A nova identidade do ensino médio como etapa da educação básica de atendimento universal impõe uma mudança de cultura e das práticas escolares. A situação exige um grande empenho para não se reproduzirem erros do passado em que se universalizou, no ensino fundamental, um modelo destinado à educação de uma minoria social que acabou por minimizar os resultados esperados da ampliação da oferta, dadas as altas taxas de evasão e repetência registradas no processo. $\bigcirc$ momento requer que se passe da expansão à reinvenção, que se recoloque o conceito de qualidade do ensino em novos termos. Um dos aspectos fundamentais a se considerar é a urgência de se criar todo tipo de incentivo e, ao mesmo tempo, de se retirar todo tipo de obstáculo para a permanência dos jovens no sistema escolar. Não se pode desconhecer que a educação média é a única política efetiva de atenção à juventude que se verifica no país, em que pesem alguns esforços mais recentes de envolvimento cultural. Não se encontra um conjunto articulado de 
políticas de atenção aos jovens que contemple os aspectos de inserção no trabalho, participação cidadã, realização de atividades culturais ou práticas sociais, o que sobrecarrega o ensino médio com expectativas às quais, até então, não era chamado a responder e às quais não pode mais se furtar.

\section{O DIRECIONAMENTO DAS REFORMAS EM EDUCAÇÃO}

As mudanças educacionais presentes a partir dos anos 80 , na maioria dos países desenvolvidos e em desenvolvimento, surgem fortemente associadas a um projeto modernizador como justificativa essencial. Segundo Juan Casassus esta é uma temática que, do ponto de vista do discurso, assegura convergência ideológica de interesses sociais diversos. A aspiração à modernidade e aos processos de modernização aparece como conceito simbólico que tende a substituir o discurso do desenvolvimento e o da revolução social, como conceito orientador das tarefas do Estado e da sociedade civil, respectivamente.

Modernidade refere-se, ainda segundo o autor citado, a um debate de ordem cultural em que predomina uma preocupação com a estética, a filosofia, as formas de compreender. A modernização, por sua vez, é expressão da modernidade na organização social e econômica, favorável ao processo de racionalização e "complexificação" das sociedades. Esse processo caracteriza-se pelo predomínio da racionalidade instrumental, eminentemente econômica e administrativa, em detrimento de uma racionalidade normativa que afeta as relações sociais no que se refere aos valores. Seu objetivo principal é o aumento da eficácia e da eficiência, com base na reformulação radical dos padrões organizacionais do sistema (Casassus, 1995, p. 14).

No campo da educação, um dos indicadores de modernização é a descentralização do sistema, com o estímulo à crescente autonomia de gestão e flexibilização das unidades escolares. Esse é um dos aspectos do movimento atual das mudanças em educação presentes nos mais diversos sistemas educativos, em que pese a diferença que impera entre eles. No início da década de 90 , vários governos nacionais introduziram mudanças significativas nos modos de gestão dos sistemas e das escolas, nas formas de financiamento da educação, nos procedimentos de decisão sobre currículos e sobre princípios e valores que devem nortear o fazer educativo.

A modernidade educacional, por sua vez, almejada particularmente nos países em processo de abertura ou de consolidação democrática, está direcionada para o aprendizado de um conjunto de valores, capaz de articular a diversidade de 
culturas e identidades, num processo de inclusão social. Examinando os anos 90, Guilhermina Tiramonti (2000) registra que a condição cidadã foi preferencialmente interpretada de uma perspectiva instrumental, como capacidade de comunicar-se mediante os diversos códigos lingüísticos. Pondera, entretanto, que, apesar da importância desta interpretação na sociedade contemporânea, a crise provocada na ordem social pelo processo de internacionalização da economia e pela preponderância de valores mercantis recoloca na pauta do dia a necessidade de se assegurarem significados socialmente compartilhados com valores, entre os quais os de solidariedade e protagonismo social.

São inúmeras as análises relativas às limitações dos processos de descentralização para cumprir seu intento de elevar a qualidade do ensino. A implementação das reformas consubstanciadas em leis, mesmo quando inspiradas em princípios de gestão democrática e participação, enfrenta obstáculos recorrentes no âmbito local, a saber, concomitância com padrões organizacionais tradicionais, cultura social e pedagógica diversa, escassa competência técnica, insuficiência de recursos financeiros, ausência de apoio de órgãos intermediários, entre outros. Não raramente os processos de descentralização têm-se mostrado disfuncionais, senão insuficientes. Pouco tem-se alterado a distância relativa, em termos educacionais qualitativos, entre os diferentes segmentos sociais. Isto porque a descentralização, sendo de caráter instrumental, é, também, um processo que comunga a complexidade dos fenômenos sociais, dada a articulação sistêmica dos aspectos que abrange. É um processo que mantém estreitos vínculos com a redistribuição ou reordenamento do poder na sociedade. Nesse sentido, tem-se verificado que a descentralização, embora abra possibilidades interessantes a um processo de modernização, é também um reflexo das relações autocráticas ou democráticas que prevalecem na sociedade, o que nos convida a uma abordagem política e não meramente técnica dessa modalidade de gestão, recolocando o papel do Estado na justa medida de suas responsabilidades com a qualidade da educação.

Analisando os novos eixos da discussão na política educacional da América Latina após os anos 90, Guilhermina Tiramonti pondera que, embora maiores margens de autonomia possam incentivar as escolas a construir um perfil institucional próprio e a dar respostas mais criativas e aderentes às problemáticas concretas que enfrentam, é preciso atentar para os limites da autonomia quando a questão em foco é melhorar a qualidade e a eqüidade do sistema de ensino. Se a articulação da escola com as peculiaridades do seu entorno e com as demandas da população que 
atende não estiver mediada por uma proposta educativa que amplie os horizontes culturais de seu alunado, o risco é o de que ela seja portadora de uma estratégia que fixe o destino dos alunos às suas condições de origem social, cultural e geográfica (Tiramonti, 2000, p. 122).

Por outro lado, a autonomia também constitui um risco em sociedades que se caracterizam por um pluralismo de caminhos divergentes, ou seja, em sociedades nas quais os diferentes grupos sociais estão distribuídos em instituições distintas, internamente homogêneas. Nesses casos, a autonomia pode estar a serviço da segregação e não propriamente da integração dos diferentes. De um lado, há a possibilidade de se ter currículos aligeirados para uma população de origem socioeconômica desfavorecida, geralmente identificada, erroneamente, como um grupo social que não valoriza a educação e, portanto, pouco afeito aos estudos e aos desafios de uma sólida escolarização. De outro, os riscos de segregação estão em uma interpretação equivocada da prática social e da contextualização que preconizam as diretrizes educacionais vigentes. Um exemplo é o sentido de solidariedade que prepondera nos ensaios de inovação do ensino médio. Boa parte das vezes, os projetos que visam educar para a solidariedade limitam-se a incentivar os jovens a ações assistenciais aos mais necessitados, fazendo total economia de um esforço no sentido de propiciar aos alunos condições e oportunidades para uma compreensão relacional dos determinantes econômicos, políticos, sociais e culturais das desigualdades sociais presentes na situação. Em que medida pode-se esperar que esses ensaios cumpram o propósito de uma formação ética, estética e política como prevêem as propostas de educação mais democráticas?

Considerados limites e possibilidades implícitos nos processos de modernização e nos movimentos em direção à modernidade, é preciso retornar ao consenso que se criou em torno da necessidade de proporcionar uma educação que possibilite o desenvolvimento global do educando, em suas várias dimensões. Isso significa uma educação que supere o paradigma predominantemente cognitivo que imperou nos currículos até os dias de hoje, abrindo-se para um conjunto de saberes, domínios e competências que respondam às transformações que vêm ocorrendo nas relações sociais e nos modos de produção e de organização do mundo do trabalho. Tais mudanças exigem um novo projeto educativo que supere a dicotomia entre o fazer e o pensar, que propicie ao educando uma formação que lhe permita mobilizar conhecimentos científicos, competências cognitivas, competências sociais e valores diante dos desafios da complexidade contemporânea. $\bigcirc$ pilar desse novo projeto está na definição dos princípios de uma educação voltada para a prática 
social e orientada para o trabalho, ou seja, uma educação básica que ao mesmo tempo articule a preparação para o exercício de uma cidadania plena e a preparação para uma inserção crítica e competente no mundo das relações produtivas, com a possibilidade de continuidade de estudos ao longo da vida.

\section{FORMAÇÃO GERAL E EDUCAÇÃO PROFISSIONAL}

É nesse contexto que se discutem a reforma do ensino médio no Brasil e sua separação da educação profissional, prevista na LDB n. 9.394/96 e consagrada no Decreto n. 2.208/97. No que se refere à posição dos gestores das políticas educacionais e de alguns segmentos da sociedade, assiste-se à celebração do modelo vigente apoiada nas críticas à estrutura anterior voltada para a profissionalização compulsória, que integrava a formação geral e profissional. Tal estrutura não logrou sucesso pela ausência de providências do Estado em assegurar as condições necessárias de implementação nas redes públicas, responsáveis pela oferta majoritária de educação escolar, dando origem à geração de simulacros de formação profissional, rejeitados em grande parte pela própria população de aprendizes. As experiências bem-sucedidas das escolas técnicas, dadas as condições especiais de funcionamento em termos de recursos humanos, financeiros e equipamentos, além de restringirem seu atendimento a um percentual ínfimo da população escolar, não cumpriram os propósitos para os quais foram criadas. Deveriam propiciar formação de alto padrão a um alunado que se dirigia ao mundo profissional, mas funcionaram mais efetivamente como cursos preparatórios de qualidade para acesso ao ensino superior, em benefício de uma população altamente selecionada. Por outro lado, a expectativa era a de que essas escolas servissem de centros de produção de conhecimentos cientíico-pedagógicos sobre a elaboração e o desenvolvimento de currículos mais abertos à integração entre os conteúdos de formação geral e a parte profissional específica, o que nem sempre ocorreu. Quando existiu, não ultrapassou os muros das próprias instituições e não serviu, como se pretendia, de referência para transformações qualitativas que se esperavam realizar no conjunto das escolas profissionais das redes públicas oficiais.

Ao mesmo tempo, fortaleceu-se a idéia de que era urgente uma educação profissional mais aderente às modernidades introduzidas no mundo do trabalho, apesar de se constatar que essa não é uma realidade presente na maioria das empresas e dos ofícios. Tal educação deveria repousar em uma base sólida de competências cognitivas de ordem elevada, de habitus mentais mais propícios à inventividade 
e enfrentamento de situações inesperadas, de uma visão mais prospectiva e assertiva dos desafios de trabalho, e de comportamentos sociais abertos à ação cooperativa. Enfim, construiu-se um consenso, em certos setores da sociedade, sobre a necessidade de um tipo de formação de caráter mais geral que servisse de base e alicerce às sucessivas e diversas formações especializadas das quais o futuro profissional haverá de necessitar, oferecida em cursos modulares de estrutura mais dinâmica e flexível.

Estas foram algumas das idéias e dos argumentos que sustentaram as justificativas, as decisões e as orientações que transferiram a formação profissional de nível técnico para um curso que, embora possa ser realizado concomitantemente com o ensino médio, caracteriza-se como um pós-médio, uma vez que o aluno somente pode receber seu certificado de técnico deste nível após a conclusão do ensino médio. Este passa a ser considerado como etapa final da educação básica de formação geral com o propósito de aprofundar e consolidar conhecimentos adquiridos no ensino fundamental.

Entre as críticas a este modelo de formação profissional separada da formação geral está a de que ele se apóia na lógica da racionalidade econômica, pela sua pretensão de pronto atendimento a presumíveis necessidades da economia, "sem estudos mais aprofundados do mercado de trabalho, apoiando-se em suposições muito questionáveis da perspectiva desse mesmo mercado, especialmente nas condições criadas pela produção" (Ferretti, 2000). Um exemplo disto é a suposição de que o mercado se pauta pelo estoque de trabalhadores qualificados, ou a de que a freqüência aos cursos amplia as condições de empregabilidade dos indivíduos. Por outro lado, a opção por uma política educacional mais focalizada no ensino fundamental, defendida pelos setores progressistas da sociedade nos anos 80, como medida de superação dos entraves quantitativos e qualitativos no processo de escolarização dos segmentos populares, vem sendo objeto de uma releitura com base na interpretação das orientações de organismos multilaterais. Esses, inspirados em teses economicistas, formuladas em face da redução crescente do mercado de trabalho, sugerem políticas restritivas para os níveis superiores ao ensino fundamental, uma vez que são de baixo retorno em situações de crise econômica como a atual. Nesse contexto, o discurso da necessidade de extensão da oferta de educação básica, aí incluída a etapa final correspondente ao ensino médio, e de expansão da educação profissional, é interpretado como um falso discurso. No caso da educação básica, essa interpretação se apóia na atenção precária à educação de jovens e adultos, matriculados em cursos diferenciados dos chamados cursos regulares, que não es- 
tão inseridos no conjunto dos alunos contemplados com os recursos do Fundef ${ }^{3}$. No que se refere à educação profissional, pela ausência de uma política de amplo espectro que atinja a massa de população, uma vez que, nos termos atuais, a maioria ainda estará excluída por não dispor das condições quer para realizar sua formação profissional, concomitante ao ensino médio, quer para realizá-la em um momento posterior.

Apesar das diferenças de posição entre os defensores da política educacional vigente e seus críticos, há um efetivo consenso sobre a necessidade de uma formação para o trabalho solidamente fundada em uma educação básica resultante da articulação de elementos diversos, como a natureza das relações sociais vividas no interior da escola, o acesso a informações e bens culturais, o domínio do conhecimento científico e tecnológico, a articulação com setores da vida produtiva, o exercício da prática social. Essa educação deve repousar em uma pedagogia aberta às transformações do mundo do trabalho e às suas repercussões profundas na vida social.

Do ponto de vista dos críticos de política vigente, essa educação somente se pode fazer presente em sociedades já desenvolvidas, em que os bens sociais e materiais estejam disponíveis a todos os cidadãos, o que não é o caso dos países emergentes premidos por alta taxa de exclusão social. No limite, uma efetiva democratização da educação somente será possível com a efetiva democratização da sociedade.

De qualquer forma, mesmo entre os críticos do modelo vigente e do movimento que procura alertar para as contradições entre a educação voltada para valores do mercado de trabalho e a educação orientada para uma democracia social e econômica, admite-se que é possível e necessário assegurar, no interior da formação geral proposta para o ensino médio: a dimensão universalista do currículo presente nos conhecimentos científico-tecnológicos e sócio-históricos publicamente valorizados; atenção às demandas do mundo do trabalho aliadas a uma compreensão dos determinantes estruturais e conjunturais das relações de trabalho e à formação pessoal e social dos educandos. Tal possibilidade supõe a superação das condi-

3. $O$ Fundo de Manutenção e Desenvolvimento do Ensino Fundamental e de Valorização do Magistério - Fundef - é um mecanismo que disciplina a distribuição de recursos financeiros entre os estados e municípios, estabelecendo critérios de cooperação entre as duas esferas federativas, com vistas a compensar desequilíbrios regionais e garantir um mínimo de investimento por aluno. 
ções de precariedade das escolas e de seus professores, uma vez que é no nível local e pelos atores envolvidos que se dá concretude ao projeto político-pedagógico da unidade escolar.

\section{DAS REFORMAS ÀS INOVAÇÕES: A MUDANÇA NO PAPEL DO ESTADO}

João Barroso, em uma análise a respeito das transformações das reformas globais promovidas pelo Estado, lembra que até os anos 80 as reformas educacionais ocorrem num contexto político do Estado Provedor, voltadas para a criação de um sistema público nacional de ensino e caracterizadas por forte centralização, no que se refere à organização e ao controle do sistema, e por uma pretendida legitimidade do Estado em interpretar as demandas da sociedade.

No final desta década, à crise do paradigma positivista e ao enfraquecimento dos critérios de racionalidade como suporte de mudanças progressistas, que já vinham se delineando nas décadas precedentes, soma-se a crítica ao burocratismo do Estado e à sua ineficiência como executor de políticas educacionais. $\bigcirc$ modelo de "reformas globais" da educação, adotado pelo Estado, a partir de um processo centralizado de decisões políticas e de orientações normativas inspiradas em uma cultura empresarial, e que pretendia uma certa homogeneidade dos processos educacionais como resposta aos desafios da modernização e da democratização, não cumpriu as promessas que cimentavam a sua legitimidade. Em muitos casos, como afirmam Tyack e Cuban (1995, p. 60 e 83), em vez de as reformas modificarem as escolas, são as escolas que acabaram modificando as reformas, uma vez que estas nunca encontram as escolas com a lousa completamente apagada. Quer por questão de sobrevivência, dadas as transformações no sistema social em que se inserem, quer por afirmação de um saber-poder que lhes é próprio, construído na prática cotidiana e norteado por um projeto de estabelecimento atento às singularidades da realidade local, os professores terminam por empregar sua "visão da prática" para produzir adaptações pedagógicas, em que o novo se articula com o velho.

A última década assistiu a uma crescente tendência em favor de uma transformação no papel do Estado, que mantém sua função de definidor de políticas educacionais, de indutor de mudanças locais e de controle de recursos e resultados, mas delega às unidades escolares a gestão do sistema.

Nesse contexto verifica-se um elevado e marcante interesse pela questão das inovações educacionais, entendidas estas, numa primeira aproximação, como mudanças produzidas no âmbito dos estabelecimentos escolares, em conseqüência 
das ações e interações dos respectivos atores sociais, expressão do poder instituinte da escola e de seus profissionais. O pressuposto é o de que essas respostas locais conduzam, com melhor propriedade, à elevação de qualidade almejada para o ensino de nível médio, e de que a divulgação desses ensaios de inovação possam ser uma alternativa promissora no processo de incentivo ao exercício da autonomia pelas escolas. As inovações teriam o condão de resgatar a educação dos impasses decorrentes do afastamento do Estado, da expansão da oferta e conseqüente incorporação de contingentes populacionais, até então excluídos da experiência de escolarização e das demandas de democratização e modernização subsumidas nas exigências de melhoria de qualidade.

Nos anos 60, a inovação foi sinônimo de mudança planejada e sistêmica, definida por peritos atuando em esferas distantes do fazer escolar, associada à idéia de modernização e desenvolvimento social e econômico. Contudo, as políticas de educação inspiradas neste conceito não chegaram a modificar a cultura das escolas, e as promessas de mudanças não foram cumpridas, pelo menos na profundidade e extensão das expectativas criadas. Nos últimos anos da década de 70 e na seguinte, as inovações adquirem um caráter de contestação. Acentua-se a luta pelo direito à educação como um direito social, entre outras reivindicações democráticas, e se produz na base um movimento inovador com ampla participação dos profissionais da educação. Surgem experiências alternativas, tanto no âmbito da educação formal como nas franjas do sistema, em atividades educativas não formais e comunitárias, das quais uma manifestação reconhecida é o movimento de educação popular. Nesses anos de acentuada crítica social, as inovações foram expressão de contestação, de militância política conduzida por aqueles que pretendiam mudar a situação vigente. Nos anos 90 tal tendência perde seu caráter "revolucionário" e adquire outros contornos diante do imperativo econômico da competitividade internacional e das complexidades sociais decorrentes do desenvolvimento tecnológico. Em um cenário de restrição de despesas e esvaziamento de seu papel provedor, os Estados viram-se compelidos a criar condições de modernização e de democratização, entre outras medidas, pela formulação de políticas e diretrizes gerais, descentralização do sistema e forte apelo indutor à participação dos educadores e das comunidades interessadas. A inovação passa a ser valorizada como estratégia política no quadro das transformações do Estado. Hoje é o sistema que exige das escolas e seus profissionais contínuo empenho inovador, sob total responsabilidade dos atores locais.

Estudos contemporâneos desnudam essa outra face das inovações ao acompanhar a trajetória de sua transformação de transgressão no plano dos valores, 
expressão de liberdade individual, para se tornar um modo de regulação local exercido pelos sistemas, na medida em que os estabelecimentos escolares são convocados a inovar, e a inovação se torna um componente indispensável da competência profissional dos educadores. Como bem lembra João Barroso (200 I), é a "adequação permanente", de que fala Dubet, ou ainda a "tirania da transformação", segundo expressão de Clarke e Newman, processo em que se transferem para os atores e a periferia do sistema as tensões e a responsabilidade pela eterna mudança, que se torna imperativa, natural e permanente, bem como o ônus dos insucessos de percurso.

\section{O CONCEITO DE INOVAÇÃO E ALGUNS DE SEUS ELEMENTOS}

Em que pese a complexidade da noção de inovação, dadas as transformações ocorridas em seu significado, e por isso mesmo, uma primeira abordagem ao assunto exige que se faça um esforço conceitual. Uma contribuição nesse sentido pode ser encontrada no trabalho de Cros e Adamczewski (1996, p. I 5-29), que busca definir inovação segundo a análise dos conceitos que lhes são próximos e que permitem situar sua posição.

De um lado, estão os conceitos de invenção, descoberta, criação, que se referem a uma novidade objetiva, da ordem do conhecimento, ou a uma novidade objetivada, da ordem do objeto, da obra ou do produto. Portanto, tais conceitos referem-se a uma novidade que não é subjetiva ou relativa ao autor, como geralmente são as inovações, mas que é certificada, socialmente reconhecida, identificada e aceita como novidade. A descoberta, a invenção e a criação são regidas por regras de homologação pública específicas: as descobertas são submetidas à comunidade científica, as invenções são patenteadas e as criações são expostas, publicadas. Os atos de descobrir, inventar e criar são atos singulares e primeiros, estão na origem e servem de referência, modelo e inspiração para transformar a realidade.

Outro conceito próximo ao de inovação é o de renovação, que significa um retorno a um estado inicial ou uma reaproximação reiterada a objetivos iniciais. $\bigcirc$ novo não se refere à novidade em si, mas à operação de retorno, à mobilização em direção a uma restauração, à reatualização que restitui a uma estado original, ao equilíbrio, ao essencial, aos valores fundamentais. Nesse sentido, para os autores em questão, a reforma é uma forma estruturada de renovação. Ao realizar o reajustamento necessário entre a sociedade e a lei, sob a forma de decretos, leis e outros ordenamentos oficiais, a reforma coloca em funcionamento um sistema que permi- 
te atingir com mais eficácia objetivos originais. Seria, portanto, uma ação de caráter conservador, uma vez que planifica uma mudança com vistas a aumentar o grau de harmonia do sistema.

A inovação, por sua vez, não se refere quer à novidade em si, seu conteúdo, quer a uma operação de retorno. Inovar significa introduzir em determinado meio algo que foi inventado, descoberto, criado anteriormente. Seu papel consiste em integrar, assimilar, adaptar novidades importadas de outros lugares. Inovar é um processo de tradução, de decodificação da novidade pura em novidade aceitável, passível de ser aplicada, com o objetivo de melhorar aquilo que existe, de introduzir em dado contexto um aperfeiçoamento, um melhor saber, um melhor fazer e um melhor ser. Diferentemente da descoberta, da invenção e da criação, que são produções que não têm necessariamente outra finalidade que elas próprias, a inovação traz embutida a idéia de estratégia de ação e é regida por objetivos práticos. A ação inovadora é da ordem da aplicação, entendida esta não como resultado de uma ação determinada, mas de um processo. Ela supõe uma intenção de mudança dentro de um projeto acalentado pelos atores envolvidos, uma intenção expressa em uma visão antecipadora, sob a forma de objetivos definidos, ou uma intenção que se manifesta em uma reação de protesto contra uma situação dada. Neste sentido, Georges Adamczewski sugere que se faça diferença entre os resultados obtidos, diante dos objetivos colocados, e os efeitos da inovação, ou seja, o impacto não esperado de sua ação, considerando-se tanto os efeitos perversos como os avanços promissores. Dada a dimensão antropológica do processo de inovação, avaliálo implica, necessariamente, analisar os significados produzidos e as transformações vividas por seus atores, em termos pessoais, sociais e intelectuais.

Outras posições podem ser identificadas nos anais do seminário Taller Internacional de Innovaciones Educativas, realizado em junho de 1995, em Buenos Aires, das quais destacamos a de Patricio Chávez e a de Ines Aguerrondo. Chávez propõe duas formas de se analisarem as inovações: de uma perspectiva instrumental ou de uma perspectiva comunicativa. Na primeira perspectiva, a mudança está centrada no produto, nos resultados, um tipo de projeto no qual um conjunto de atividades é realizado para se gerar um produto. Na concepção de inovação como ação comunicativa, levam-se em conta posições diferentes dos atores envolvidos e a necessidade de negociação. Nesse caso, integra-se o processo no produto e o resultado é um processo consolidado na inovação. Ou seja, Chávez parte de uma visão epistemológica da escola como espaço único, específico, com sua própria identidade e atores distintos. É nesse espaço que a política educacional definida legitima- 
mente pelo Estado deve ser debatida, analisada, reconstruída, para que tenha uma concretização institucional. As inovações seriam resultantes da construção da identidade da escola, mediante trabalho coletivo que consolide interesses e posições distintas diante de compromissos comuns assumidos. As inovações, portanto, constituem projetos que fazem parte da proposta educacional da escola e que resultam de um processo de negociação entre portadores de visões e posições políticoeducacionais diversas.

É provável que haja alguma proximidade entre esse conceito de inovação como comunicação, que por sinal lembra a obra de Paulo Freire (1983), Extensão ou Comunicação?, da década de 60, e o conceito de inovação como "tradução", que Françoise Cros (1997a) destaca, ao analisar os trabalhos de uma equipe de pesquisadores do Centro de Sociologia das Inovações, ligado à École des Mines, na França. Na perspectiva desses estudos, a inovação não se transmite como uma epidemia, nem por um processo de influência ou de conflito, mas por efeitos sucessivos de tradução entre diferentes atores, diante de um mesmo objeto. A tradução seria esse modo de se exprimir sobre um mesmo objeto, que tem repercussões nas preocupações e representações dos diferentes atores, e atende a uma espécie de bem comum provisório desses diferentes atores. Nesse caso não haveria, de um lado, um objeto e, de outro, uma apropriação desse objeto, essas duas operações estariam consubstancialmente ligadas no processo de inovação.

A contribuição de Ines Aguerrondo ( 199 |), por sua vez, reflete uma particular atenção à complexidade da temática ao propor um paradigma conceitual. Ela advoga a idéia de que inovar é produzir transformações estruturais. Como um fenômeno social, a educação é também portadora das características de um sistema complexo, ou seja, é uma totalidade, síntese de múltiplas determinações, formada por subsistemas fortemente interrelacionados, forças opostas que funcionam numa lógica dialética em que existem elementos estruturais e elementos fenomênicos. Aspectos fenomênicos são os aspectos externos, aparentes do modelo educativo. Mudanças nesses aspectos significam ajustes, melhorias, aperfeiçoamento do modelo. Aspectos estruturais são as formas que dão suporte ao sistema, formas básicas, independentemente da maneira como se expressam no modo de existir. Mudanças nos aspectos estruturais é que podem ser consideradas como inovações. São mudanças que refletem uma ruptura no equilíbrio do sistema.

Dentre os vários elementos que funcionam como organizadores da estrutura básica da educação estão: a definição do papel da educação na sua relação com a sociedade, a concepção de ciência e conhecimento, as concepções de ensino e 
de aprendizagem, a idéia sobre as características psicológicas do ser que aprende, entre outras. Esses eixos determinam questões específicas da organização da educação, quer no nível do sistema, como características e duração dos níveis e ciclos, modalidades de cursos, quer na organização dos planos intermediários, como por exemplo a definição da função das diretorias regionais, do papel da supervisão, quer, ainda, no âmbito das características das escolas.

.... explicitação destas características fundantes da estrutura básica do sistema educativo é o que permite diferenciar, em cada situação concreta de mudança educativa, a presença de uma melhoria ou reacomodação, ou de uma transformação. Esta só se dá quando a intenção de mudança ou a experiência empreendida se propõe a afetar alguma destas bases sustentadoras de um sistema educativo. Se uma experiência de mudança não afeta estes eixos fundantes, não se pode falar em sentido próprio de inovação, já que só se tratará de uma melhoria do sistema vigente e não de sua transformação. (Aguerrondo, 1991, p. 23)

Ao se adotar uma teoria de aprendizagem, realiza-se uma ação que pode levar a decisões de mudanças na organização do sistema de ensino, de uma estrutura rígida para modos de organização mais flexíveis, como a adoção do regime de ciclos escolares, da pedagogia da alternância, por exemplo, que somente se completa como ação inovadora se repercutir em decisões do corpo docente no nível da escola e da sala de aula. Mudança estrutural, portanto, não significa mudança no plano macroglobal, ainda que existam aspectos estruturantes que têm a ver com decisões nacionais. Muitos dos aspectos estruturais básicos do sistema educativo expressam-se, unicamente, no nível da escola e inclusive no âmbito da aula, o que coloca em posição de particular relevância o papel do professor no processo de escolarização.

Segundo a referida autora, a perda de qualidade que se registra em educação deve-se ao fato de que os eixos fundantes que estruturam a realidade educativa nos dias atuais são os mesmos vigentes à época da instituição dos sistemas escolares, portanto, seculares e inadequados para os novos tempos.

Em uma linha complementar de entendimento estão os conceitos que destacam na inovação a questão do significado. Inovar seria fazer de outra maneira ou pensar de outra maneira? A tendência predominante parece ser esse vezo operativo de buscar sempre a melhor forma e o procedimento certo para cada situação. Um exemplo do que se afirma são as reproduções vazias de sentido, uma resposta técnica a problemas de ordem muito mais complexa, envolvendo aspectos políti- 
cos, antropológicos, existenciais. $\bigcirc$ essencial da inovação é o sentido que se constrói, a nova maneira de ver aquilo que já existe e o que já é realizado. Representações, valores, significados compõem o núcleo básico do conceito de inovação em educação.

Quanto à relação reforma-inovação, há os que consideram que as reformas introduzem elementos que aspiram melhorar o sistema de ensino, mas que dependem das inovações como um meio fundamental para se realizarem as transformações necessárias. Segundo Tedesco, existe uma tendência "responsiva" das inovações. Usualmente as escolas elaboram suas propostas educativas dentro dos parâmetros de uma política de educação.

Françoise Cros (1997a), a partir de estudo recente por ela conduzido em países da Comunidade Européia, sugere colocar a reforma e a inovação não em pólos opostos, mas em um cenário de complementaridade: as reformas passam a constituir o quadro dentro do qual as inovações se desenvolvem. A reforma é uma ação própria das autoridades e as inovações são produzidas pelos atores em seu cotidiano. Uma das reflexões que se têm feito é que a chave pode estar nos espaços intermediários, ocupados pelos agentes de mudança, cuja missão não é a de controle, mas de acompanhamento, ou, ainda, de regulação. Uma análise das posições intermediárias da hierarquia dos sistemas, em especial a dos inspetores ou supervisores de ensino, mostra que suas atribuições não são bem definidas e que gozam de um espaço de liberdade maior do que se pode imaginar. Em suma, são posições que merecem atenção no estudo das inovações que acontecem nas escolas.

\section{INOVAÇÕES INTRODUZIDAS PELAS ESCOLAS}

Quais as mudanças que as escolas vêm ensaiando? Quais as interpretações que vêm fazendo das orientações legais vigentes e como estas se refletem em suas práticas? Como interpretá-las à luz de um ideário político-pedagógico inspirado em valores democráticos que perseguem uma melhoria de qualidade da educação para todos? Quais as possibilidades de que estas experiências produzam conhecimento acumulado, sejam apropriadas pelas escolas e conduzam ao avanço qualitativo que se espera? Alguns elementos para responder a estas questões foram colhidos mediante a análise de projetos escritos, concebidos e desenvolvidos por escolas públicas de nível médio, e em atividades de relatos de experiências realizadas no processo de implantação do Programa de Melhoria e Expansão do Ensino Médio, do Estado de São Paulo, a partir do ano 2000. 
Os relatos das escolas não são uma amostra do que ocorre na rede pública estadual como um todo, mas apontam indícios de que as escolas, quer por pressão das transformações sociais em curso, manifestas nas expectativas dos alunos, da comunidade e da sociedade em geral, quer por convicção profissional de seus educadores, quer, ainda, por indução do Estado, estão realizando ensaios de inovação. Nesses ensaios são priorizadas questões referentes à gestão escolar e ao trabalho coletivo, à formulação e desenvolvimento da proposta educativa, com particular ênfase em ensaios de integração e contextualização de conhecimentos, à articulação com agências externas para o desenvolvimento de projetos educativos, ao estímulo do protagonismo dos jovens e à sua identificação com a instituição.

No que se refere à gestão, os novos processos desenvolvidos pela escola apontam para um maior envolvimento de professores, pais e alunos e para uma abertura de relações com a sociedade civil. Uma situação particular, que ilustra os avanços e as dificuldades das escolas nesse aspecto, foi a descentralização de recursos financeiros às unidades escolares promovida pelo Programa de Melhoria e Expansão do Ensino Médio do Estado de São Paulo. Esses recursos foram destinados à aquisição de materiais pedagógicos, equipamentos e pequenos reparos na estrutura física dos estabelecimentos, considerados necessários a um melhor desenvolvimento das propostas pedagógicas formuladas pelas escolas nos seus próprios termos. Boa parte dos diretores informou que a escola envolveu os professores, a Associação de Pais e Mestres e o Conselho de Escola. Em alguns estabelecimentos o Grêmio participou do processo, e em outros o convite para colaborar se estendeu a todos os pais e alunos. Houve casos em que os chamados "amigos da escola", pessoas que não são membros da comunidade escolar mas que com ela colaboram porque se interessam pelo trabalho desenvolvido, deram uma contribuição interessante, colocando seus conhecimentos profissionais à disposição no processo de investimento dos recursos financeiros. Algumas escolas recorreram aos meios de comunicação de massa para informar a comunidade local sobre o Programa de Melhoria e Expansão do Ensino Médio e sobre os recursos recebidos. Rádio e jornal foram utilizados para comunicar à população os critérios e as opções de compra de materiais pedagógicos e para convidar os munícipes a visitarem a escola e conhecerem os materiais em sessão pública de apresentação pelos alunos ou, ainda, mediante atividades de manuseio dos próprios materiais.

Tais procedimentos revelam um empenho em construir uma relação de reciprocidade com a sociedade civil que vai além de um trabalho evidente de prestação de contas ou de uso da comunidade para preencher lacunas do Estado. Do 
ponto de vista da formulação e do desenvolvimento da proposta pedagógica da escola, a autonomia para administrar a aplicação de recursos financeiros mostrou-se uma oportunidade fértil de fortalecimento do trabalho coletivo dos professores e da centralidade do currículo como critério básico para as opções de investimento. Enquanto algumas escolas fizeram suas escolhas partindo do catálogo de materiais produzido e divulgado pela Secretaria de Estado da Educação, outras iniciaram o processo por uma redefinição do projeto educativo em vigor, tendo em vista os indicadores de avaliação interna e externa existentes, as discussões e levantamento de expectativas com os alunos, e enfim, a decisão sobre os trabalhos que deveriam ser desenvolvidos no ano seguinte. Somente depois, à vista do projeto reformulado, estabeleceram prioridades, consultaram o cadastro e definiram a aplicação dos recursos.

As opções variaram bastante: compra de materiais de apoio pedagógico para determinada área considerada prioritária na proposta pedagógica da escola para melhoria do ensino; reorganização da biblioteca como centro de cultura; assinatura de jornais e revistas; reconstrução ou montagem de laboratórios e salas-ambiente; aplicação de recursos para o desenvolvimento de projetos juvenis ligados a rádio escolar, jornal do estabelecimento, teatro, competições esportivas. Boa parte das unidades escolares priorizou a complementação de recursos da sala de informática, elevando o número de equipamentos, providenciando mobiliário necessário ou fazendo as adequações físicas que o ambiente solicitava.

Um aspecto que ganhou evidência nos relatos foi a decisão das escolas de ampliarem os espaços de aprendizagem dos alunos. As orientações para aplicação dos recursos previam a possibilidade de serem também canalizados para pequenas adequações de espaços físicos, o que parece que certas escolas fizeram com propriedade. Imbuídas de uma concepção mais inovadora de educação escolar, que substitui o restrito espaço da sala de aula pelo ambiente físico e institucional do estabelecimento escolar como o locus da aprendizagem e da reconstrução do conhecimento, algumas escolas otimizaram espaços, recuperaram compartimentos e aumentaram as possibilidades de os alunos usufruírem das mais variadas situações de estímulo à aprendizagem. Exemplos disso são um jardim interno que se transforma em praça de leitura, um galpão que é recuperado como sala de multimeios, um espaço de função indefinida que se torna sala de encontro e "bate-papo" para os alunos, um canto que se converte em local de trabalho e estudo individual ou para pequenos grupos.

A preocupação com a organização e o uso do material didático adquirido levou as escolas a diversas soluções e providências. Em algumas delas os professo- 
res em geral, sem distinção de áreas, tiveram oportunidade de conhecer e manipular todos os materiais adquiridos, que acabaram sendo disponibilizados em uma sala comum, ampliando as possibilidades de otimização de uso e de um trabalho curricular mais integrado. Outras, atentaram para a necessidade de capacitação dos professores para uso dos novos materiais. Para isso lançaram mão dos conhecimentos existentes entre os pares, pais, alunos, ex-alunos e de especialistas de instituições parceiras ou das próprias empresas responsáveis pela fabricação do material.

Os efeitos dessas novas experiências, relatadas pelas próprias escolas, parecem significativos: maior envolvimento dos professores com a qualidade do projeto educativo formulado e desenvolvido pela escola; pressão dos alunos para uma maior dinamização das aulas mediante o uso do material didático disponível; elevação nos índices de freqüência dos alunos, maior respeito à preservação do patrimônio escolar; aumento da demanda da comunidade por matrículas nessas escolas, entre outros.

Esses relatos, circunscritos a uma situação específica de aplicação de recursos pela escola, revelam que é possível identificar na rede pública do estado ensaios de um fazer pedagógico de caráter mais autônomo, atento às suas relações com a sociedade civil, sensível aos desafios de construção de um ensino centrado no currículo, com um acento particular no incentivo à participação dos alunos.

Pode-se observar, nos relatos das escolas, maior sensibilidade para promover o que se tem chamado de "protagonismo juvenil". As escolas têm procurado cativar os alunos mediante um conjunto de atividades que falem mais de perto a seus interesses e necessidades: esporte, teatro, música, debate sobre drogas, meio ambiente, violência. Pesquisas realizadas entre os jovens revelam que suas expectativas envolvem tanto questões relativas ao ensino e aprendizagem quanto questões referentes ao ambiente social que a escola pode propiciar. Esperam que os professores incentivem sua aprendizagem e auto-estima e desenvolvam aulas mais interessantes, que tenham referência em suas experiências de vida, estabeleçam uma interação de respeito mútuo com os alunos, utilizem os equipamentos e laboratórios disponíveis, enfim desenvolvam aulas que os motivem a aprender. Mas esperam também que a escola seja um espaço agradável, com atividades culturais, esportivas e sociais, em que possam encontrar amigos, ouvir música e namorar (São Paulo, 2000).

Uma pesquisa realizada sobre os jovens do ensino médio e suas representações sociais (Franco, Novaes, 200 l, p. 179) confirma a percepção que os jovens têm da escola como espaço de sociabilidade significativo em suas vidas. A escola é um lugar de "fazer amigos e conviver com pessoas", particularmente para os alunos 
procedentes de estratos sociais menos favorecidos, que já assumem responsabilidades familiares e profissionais e que, dispondo de um espaço estrito de tempo para o lazer, não encontram em suas comunidades qualquer equipamento público em que possam desenvolver outros tipos de atividades. Sensíveis a essas expectativas, e interessados em diminuir o absenteísmo e a evasão, algumas unidades da rede pública estadual vêm introduzindo atividades que induzem o alunado a uma maior identificação com a escola, estimulando o desenvolvimento de iniciativas, o trabalho cooperativo, a assunção de responsabilidades. Várias escolas já contam com rádios organizadas e conduzidas pelos próprios alunos. Algumas dessas experiências atendem ao interesse da direção e do corpo docente em manter os alunos relativamente disciplinados durante os intervalos de recreio, entrada e saída, com uma programação tipicamente voltada aos interesses dessa faixa etária. Outras, entretanto, já estimulam o comportamento pró-ativo dos alunos, que são convidados a apresentar programações, realizar consultas entre os pares e os professores, formular critérios de seleção de programas, procurando articular as expectativas dos alunos ao desenvolvimento do projeto pedagógico da escola. Em localidades pequenas, há escolas que avançam ainda mais no potencial educativo e cultural deste tipo de projeto. A rádio é colocada à disposição da comunidade e atende às suas necessidades de informação e articulação entre pessoas.

Há progressos significativos no que se refere à relação com a comunidade. A "abertura para fora" vai além do envolvimento da comunidade na gestão democrática da escola. Ela penetra as questões do currículo e justifica a organização de práticas que assumem um caráter social mais amplo. Vários são os exemplos: escolas que, ao orientar a elaboração de um jornal do estabelecimento, celebram acordos com a Prefeitura Municipal e passam a estender a sua distribuição à comunidade local; projetos de prevenção de doenças sexualmente transmissíveis cujo material informativo, produzido pela escola, é distribuído em barraca instalada na feira de legumes e frutas, montada semanalmente nas imediações da escola; arborização de bairros em colaboração com a administração da localidade e da população, a partir de projetos de preservação do ambiente.

Outros depoimentos, entretanto, revelam práticas de relação com a comunidade que se revestem de caráter assistencial. A distribuição de cestas básicas para populações carentes é um exemplo desse tipo de iniciativa inovadora adotada pelas escolas. Em que pese o fato de que desenvolver atitudes de solidariedade seja um dos propósitos de formação geral e humanística dos educandos, é preciso atentar para a possibilidade de que essas atividades não estejam propriamente orientadas 
para "práticas sociais" no sentido em que estão previstas nas finalidades definidas na nova LDB. Isso porque tais atividades nem sempre se fazem acompanhar de um esforço de compreensão relacional dos determinantes econômicos, políticos, sociais e culturais das desigualdades sociais presentes na situação e, conseqüentemente, não propiciam a reflexão e o preparo do aluno para uma maior atenção às alternativas de intervenção na realidade que as origina e as multiplica.

A abertura para a comunidade também ocorre mediante ensaios de inovação que têm origem fora da escola, em uma Secretaria Estadual ou Municipal do Meio Ambiente, da Agricultura, da Saúde, da Cultura. São relações promissoras do ponto de vista do enriquecimento da proposta educativa da escola. De fato, há escolas que se apropriam dos projetos de seu interesse, integram-nos ao seu projeto de currículo, aprofundam e ampliam nas direções apontadas pelas reflexões e necessidades locais, identificadas pela sua equipe de educadores e por seus alunos. Outras, entretanto, têm dificuldade de equacionar a relação entre projetos de origem externa e projetos próprios e se vêem assoberbadas com a quantidade de projetos que acabam sendo induzidas a desenvolver. A probabilidade de que o façam de forma superficial, com pouco proveito para a construção de competências pretendidas pelo aluno, é muito grande.

Merece destaque especial a observação de escolas que, preocupadas em assegurar uma fundamentação teórica ao fazer docente, demonstram uma apropriação inadequada de conceitos que passam a justificar decisões pedagógicas equivocadas, quer do ponto de vista da função social da escola, quer da perspectiva da própria teoria que as informa. Um exemplo disso é o uso de conceitos teóricos de autores consagrados na literatura pedagógica para caracterizar grupos de alunos como inaptos para o trabalho escolar, por se encontrarem fora da "zona de desenvolvimento proximal", e a conseqüente sugestão de apelo às famílias desses alunos de ensino médio para que tomem as devidas providências, já que os mesmos não estão interessados no ensino.

É preciso um olhar sério, ainda que sereno, sobre tais situações. As escolas devem sempre ser incentivadas, senão induzidas a fundamentar teoricamente seu trabalho, mas que o façam gradativamente, à medida que dominam conceitos, procedimentos e critérios de validação próprios da teoria adotada.

Ainda, nessa linha de considerações, registra-se o caso de escolas que procuram assessoria para os problemas de indisciplina e desinteresse dos alunos. Uma fundamentação teórica unilateral, essencialmente psicológica, tem levado escolas a identificar a causa dessas dificuldades na baixa auto-estima do aluno, e a desenvolver 
projetos inovadores com vistas a elevar o autoconceito dos alunos apoiados em uma interpretação do problema como decorrente de fatores externos à escola, como relações familiares e sociais, dificuldades no trabalho, entre outras. Nesses ensaios de melhoria, as escolas são preservadas de qualquer responsabilidade no comportamento dos alunos. São o centro das preocupações da escola, mas suas dificuldades escolares não conseguem sensibilizar os docentes, funcionários e equipe dirigente a fazer uma reflexão sobre possíveis fatores intra-escolares.

Pesquisas já realizadas demonstram que não é propriamente a necessidade de trabalhar que leva os jovens a abandonarem a escola, na verdade os que trabaIham são os que se encontram em melhores condições de a freqüentar, por terem algum recurso para as despesas decorrentes. Os jovens se afastam da escola porque ela é o espaço da indiferença, da passividade, ao qual não se sentem pertencer. Pode-se dizer, ao contrário, que é a escola que abandona os jovens com seu vezo academicista, distante das experiências de vida e dos desafios enfrentados por esses jovens. É, portanto, compreensível o empenho das escolas em propiciar oportunidades para que o aluno com ela se identifique, em um processo que poderíamos chamar de "cooptação sedutora", mas que traz também os riscos de um distanciamento de suas reais funções como instituição destinada à formação escolar de seus alunos. Há ainda o risco, e este é o mais freqüente, de que as escolas se lancem em inúmeras atividades paralelas que não tenham qualquer reflexo na substituição necessária do seu tradicional paradigma de ensino. Em alguns desses ensaios percebese que a escola vem assumindo características mais próximas às de um clube, uma associação de lazer, uma entidade assistencial, um espaço de animação cultural do que propriamente as características de uma instituição de ensino. A escola é o lugar em que se cultiva a relação com o conhecimento. Lugar em que o aluno deve ter oportunidade de confrontar seu saber de vida espontâneo com o saber sistematizado, e de construir esquemas intelectuais e de ação para interpretar, compreender e participar intencionalmente das relações sociais e da prática produtiva. Hoje, essa concepção de saber contempla o desenvolvimento geral do aluno, em suas múltiplas dimensões. Embora não haja uma relação de hierarquia entre os diferentes saberes, a dimensão cognitiva, que supõe conhecimentos e capacidades intelectuais, está no cerne do fazer específico da escola, que é o ensino. Há uma preocupação com uma tendência à dispersão no cotidiano das escolas, tal como ocorreu nos anos 50 e 60, quando se procurou expandir a oferta de ensino fundamental para as camadas populares da sociedade, estendendo além dos quatro anos de escolaridade obrigatória. $\bigcirc$ ativismo pedagógico decorrente de um entendimento aligeirado das idéias pedagógicas de aluno participante, centro do processo educativo, prolife- 
rou na ausência de um compromisso político com a democratização de um ensino de qualidade para todos.

O mesmo risco pode ser identificado em ensaios de inovação voltados para o desenvolvimento de projetos educativos nas escolas. Registra-se uma grande dificuldade dos docentes entenderem os projetos educativos como uma forma de desenvolvimento da proposta curricular da escola mais integrada e propícia à contextualização e ao desenvolvimento de competências, com particular ênfase no comportamento pró-ativo do aluno. Em regra os projetos educativos são desenvolvidos como apêndices curriculares, paralelos, sem articulação com as disciplinas do currículo, que continuam a ser ministradas de forma isolada, abstrata e descontextualizada. Essas concepções equivocadas do que é um projeto educativo são flagradas quando professores solicitam mais algumas aulas no horário semanal para o desenvolvimento de projetos específicos, ou quando nomeiam como projetos interdisciplinares eventos pontuais com rala vinculação com a construção do conhecimento como processo. Nesses casos, os projetos parecem servir mais como uma "pausa pedagógica", para proporcionar um ambiente social de descontração, do que corresponder a uma nova concepção de educação e aprendizagem.

Mas, qual a representatividade destas experiências, considerada a totalidade das escolas? Qual a possibilidade de que venham a contaminar outras escolas na construção de alternativas de ensino mais interessantes e eficazes da perspectiva da formação dos alunos, dada a diversidade de condições e a habitual anomia reinante? Em que medida estes ensaios são efetivamente apropriados, incorporados como práticas cotidianas no trabalho institucional e docente da própria escola que os realiza? E, principalmente, quais os riscos de que inovações bem intencionadas conduzam a resultados inócuos, senão totalmente contrários, aos pretendidos nesse processo de redirecionamento do ensino médio?

Os relatos e as observações destacados neste trabalho não representam um retrato das escolas da rede pública estadual, mas sinalizam o campo de possibilidades de melhoria existente. Certamente as condições em que esses relatos são feitos são propícias para uma apresentação mais asséptica e higienizada dos aspectos negativos, das dificuldades, das dúvidas, dos embates. É muito provável que o "efeito de halo", proporcionado pela participação no programa e pela visibilidade da escola, obscureça limitações: pouca adesão de professores; disputas entre áreas ou disciplinas para alcançar privilégios na distribuição dos recursos financeiros; comunidades desarticuladas e sem condições de oferecer um apoio e colaboração consistentes à escola; transferência de quase a totalidade dos professores nos processos de remo- 
ção anual; compra de materiais que os docentes não têm condição de utilizar, além de outras já apontadas neste estudo.

A questão principal, entretanto, não está nos aspectos que os relatos omitem. Sua divulgação não deixa de ser interessante, pois suscita a reflexão dos professores e amplia o horizonte de alternativas de melhoria do ensino nos termos de cada estabelecimento de ensino. A questão principal está no pressuposto equivocado de uma correlação positiva, incontestável, entre autonomia e melhoria de qualidade das escolas e no seu corolário: a ampliação dos espaços de autonomia das escolas e o controle, pelo sistema e pela sociedade civil, sobre seus resultados asseguram elevação de qualidade. Conseqüentemente, o que se observa é uma ausência do Estado no acompanhamento, orientação e apoio às unidades escolares. Pouco se conhece sobre a vida das escolas: seus desafios, suas dúvidas, suas opções, seus sucessos efêmeros, não apropriados na cultura pedagógica dos professores, seus avanços e retrocessos. E quando se tem esse conhecimento permanece o distanciamento ditado por um mal-entendido "respeito" à individualidade da escola. Uma ilustração do que se afirma é o fato de que os Planos Anuais de Ação das Diretorias Regionais, até recentemente, permaneceram omissos em relação às necessidades específicas de assessoria às escolas que oferecem o ensino médio, mesmo após o novo ordenamento legal estabelecido pela LDB de 96, as Diretrizes Curriculares Nacionais de 98 e os incontáveis estudos realizados nos centros de pesquisas e nas instituições de ensino superior.

Em parte é a escola que se recusa a ser a responsável solitária pelos ensaios de inovação que vier a conduzir, comportamento que é interpretado, em geral, como "resistência às mudanças". Não há, entretanto, um investimento para qualificar esta "resistência". Será resultante de concepções acadêmicas que entram em conflito com os fundamentos teóricos da reforma pretendida? É conseqüência de posições ideológicas distintas? Decorre de uma insegurança natural diante das situações novas e das incertezas de sucesso na substituição de sólidas práticas construídas no exercício profissional? É fruto de uma reivindicação de maior presença do Estado por meio das equipes de supervisão e de orientação pedagógica das Diretorias Regionais? Será a recusa ao peso da pressão por adaptação constante em condições profissionais e sociais adversas?

A necessidade de apoio às escolas não é de pequena monta. Além das dificuldades até aqui apontadas, alguns exemplos podem ser citados: a abertura para maior flexibilização da organização administrativa e curricular das escolas, legalmente apoiada, pouco tem beneficiado os alunos e o trabalho das disciplinas com projetos, uma vez que esses continuam a ser interpretados como procedimento de ensino parale- 
lo e exterior às atividades tradicionais desenvolvidas em classe; escassa atenção vem sendo dada às especificidades do período noturno, que abarca a maioria das matrículas do ensino médio e atende o aluno trabalhador; são ainda tímidas as experiências de integração e contextualização curricular, algumas vezes fruto de uma compreensão parcial, ou mesmo equivocada, dessas diretrizes pedagógicas; formação dos alunos para desenvolvimento de atitudes solidárias reflete-se em atividades de assistencialismo social que pouco contribuem para a compreensão dos condicionantes estruturais das condições de desigualdade e para a prática de intervenção social; ausência de articulação com o mundo do trabalho, reforçando uma tendência a idealizações abstratas nas representações dos jovens sobre a organização e as regras de produção do mundo do trabalho (Franco, Novaes, 200।, p. |8|-|82); ênfase em um "protagonismo juvenil" que se exerce em aspectos periféricos da vida escolar, sem considerar a centralidade do ensino e da formação cidadã.

Não são pequenos os riscos de uma atenção à diversidade que obscureçam os avanços obtidos no campo da igualdade. João Barroso, referindo-se à produção sobre o assunto na França, afirma que “...outros autores interrogam-se se não é necessário 'recuperar' o sentido da reforma enquanto intervenção legítima de uma representação nacional fundada na legitimidade democrática" (200 I, p. 14).

É possível que estejamos no limiar de um novo movimento.

\section{REFERÊNCIAS BIBLIOGRÁFICAS}

AGUERRONDO, I. Innovaciones y calidad de la educación. Revista Latinoamericana de Innovaciones Educativas, v. 3, n. 4, p. 17-42, 1991.

BARROSO, J. Das reformas globais às mudanças locais. Simpósio Brasileiro de Política e Administração da Educação, 20. Anais... Salvador: Anpae, 2001.

CASASSUS, J. Tarefas da educação. Campinas: Autores Associados, 1995.

CROS, F. L'innovation à l'école: son sens, sa place. Cahiers Pédagogiques, n. 350-35I , p. 1922, 1997.

. L'Innovation en éducation et en formation. Revue Française de Pédagogie, n. I I8, p. 127-156, jan. mar. 1997a.

CROS, F.; ADAMCZEWSKI, G. L'Innovation en éducation et en formation. Bruxelas: De Boeck Université, 1996.

FERRETTI, C. J. Mudanças em sistemas estaduais de ensino em face das reformas no ensino médio e no ensino técnico. Educação \& Sociedade, v. 21, n. 70, p. 80-99, abr. 2000. 
FORQUIN, J.-C. Evoluções recentes do debate sobre a escola, a cultura e as desigualdades na França. In: FRANCO, C. (org.). Avaliação, ciclos e promoção na educação. Porto Alegre: Artmed, 2001. p. I01-120.

FRANCO, M. L. P. B.; NOVAES, G. T. F. Os Jovens do ensino médio e suas representações sociais. Cadernos de Pesquisa, n. I12, p. 167-183, mar. 2001.

FREIRE, P. Extensão ou comunicação?7.ed., Rio de Janeiro: Paz e Terra, 1983.

GUIJARRO, R. B.; RAIMONDI, G. M. Estado del arte sobre las innovaciones educativas en América Latina. Santafé de Bogotá: Convenio Andrés Bello, 2000.

HAVELOCK, R. G.; HUBERMAN, A. M. Innovation et problèmes de l'éducation: théorie et réalité dans les pays en développement. Paris: Unesco, 1980.

KUENZER, A. Z. O Ensino médio agora é para a vida: entre o pretendido, o dito e o feito. Educação \& Sociedade, v. 21, n. 70, p. 15-39, abr. 2000.

MELLO, G. N. O Ensino médio em números: para que servem as estatísticas educacionais. Brasilia: MEC/Inep, 1999. p. 91-108.

MITRULIS, E. Ensino médio: um olhar sobre a prática das escolas. In: Congresso Estadual Paulista sobre Formação de Educadores, 6. Anais do... Águas de Lindóia: Unesp, 2001.

NICOLLET, M. Innovation et décentralisation: quel processus d'innovation en Suisse? In: CHARLOT, B.; BEILLEROT, J. (orgs.). La construction des politiques d'éducation et de formation. Paris: Presses Universitaires de France, 1995. p. 213-218.

SÃO PAULO (Estado). Secretaria de Estado da Educação. Circuito gestão, mod. II: Gestão pedagógica, p. 55-56, 2000.

SARMIENTO, S. Innovar, innovar y seguir innovando... Disponível em: < http:// foro.unesco.cl> . Acessado em: set. 2001 . [Participação no Fórum Unesco: Proyecto Regional de Educación de 200/ a 2015]

SEMINARIO TALLER INTERNACIONAL DE INNOVACIONES EDUCATIVAS. Revista Latinoamericana de Innovaciones Educativas. Buenos Aires: Ministério de Cultura y Educación de Argentina/OEA, v. 7, n. 20, p. II-7I, 1995.

TIRAMONTI, G. Após os anos 90: novos eixos de discussão na política educacional da América Latina. In: KRAWCZYK, N.; CAMPOS, M. M.; HADDAD, S. (orgs.). O Cenário educacional latino-americano no limiar do século $X X \mathrm{X}$ : reformas em debate. Campinas: Autores Associados, 2000. p. I 17- 140.

TYACK, D.; CUBAN, L. Tinkering toward utopia: a century of public school reform. Cambridge, Massachusetts: Harvard University Press, 1995. 